\title{
All-GFRP footbridge under human-induced excitation
}

\author{
Beata Stankiewicz ${ }^{1, *}$, Piotr Górski ${ }^{1}$, and Marcin Tatara ${ }^{1}$ \\ ${ }^{1}$ Opole University of Technology, Department of Roads and Bridges, Katowicka 48, Opole 45-061, Poland
}

\begin{abstract}
The dynamic behavior of lively footbridge is a complex problem. Recently there were numerous publications and recommendations related to the dynamic nature of footbridge. The complicated procedure which was set in a number of instructions and standards says nothing about actions aimed at avoiding critical frequency range in structure. In the paper, results of dynamic in-situ tests of cable-stayed all-GFRP (Glass Fiber Reinforced Polymer) footbridge are presented. Fiberline Footbridge, located in Kolding city in Denmark, was constructed in 1997 using 12 different pultruded profiles all made of GFRP material. The dynamic characteristics as well as vertical response of the tested footbridge under human excitation are given and discussed. Firstly, in order to estimate the dynamic properties of the footbridge, a series of freedecay responses under human jumping were conducted. The fundamental frequency of the analyzed structure was within a critical range. A methodology for footbridge classification with regard to their dynamic sensitivity was worked out and the correlation between the structure's properties and its dynamic response under pedestrian excitation was formulated. It was found that the analyzed footbridge fulfilled vibration comfort criteria elaborated by technical guide Sétra, however, more restricted acceleration limits suggested by Eurocode were not met.
\end{abstract}

\section{Introduction}

The trend toward the constructing of light and flexible footbridges design to actuality the necessity of development of mechanical solutions for mitigation of vibrations induced by both the wind and pedestrians [1]. However, it has been reported in the literature that when comparing to measurements a force model can overestimate the responses. In this finding a hypothesis is raised that an interaction between structure and pedestrian plays important role in some situations, and this affects the response. On the other hand, it has been discussed that, in crowd situations, moving pedestrians can potentially increase the damping of the system and thereby reduce the magnitude of structure response, in a similar fashion as it occurs when the damping of the system is increased by people standing still [2].

One of the basic scientific problems of contemporary bridge engineering in relation to footbridges is their dynamic sensitivity. Modern footbridges are more sensitive to vibrations. It is caused by technologically advanced materials used for their construction, which have better strength parameters than those used before. Other toward important reason is a trend started several years ago designing typical and original structures. Apart from the progress in material technology, a factor which makes it possible to meet engineering challenges is the development of computer software, which allows solving complex design problems [3]. The complicated procedure which was set in a number of instructions and standards says nothing about actions aimed at avoiding critical frequency range in structure. Of course, in many spectacular footbridges effective change of range of selffrequencies is impossible. However, there are a lot of bridges, where the problem of excitation by pedestrians can be excluded or limited by smart design of stiffness and mass distribution in the structure. Such action can often avoid critical frequency ranges and minimize their expenses on additional artificial damping [4].

Lightweight bridges in general display multiple modes in that frequency range or below, whereas the modal mass of these modes is relatively small. For this case the load component of higher or sub-harmonics is already sufficient and the amplified vibrations cause already significant accelerations. Also it has been observed that these weak structures respond to the forced vibrations and that the resulting vibrations are already significant even without a resonant amplification [5].

Glass Fiber-Reinforced Polymer (GFRP) pultruded profiles have great potential in the construction industry, presenting certain advantages when compared with traditional materials, including the potentially improved durability under fluctuating levels of environmental factors. GFRP composite material is one of the most innovative materials being slowly introduced in contemporary bridge structures. There are several key advantages of the material (GFRP) such a high strength, low self-weight, corrosion resistance, ease of installation, electromagnetic transparency. GFRP has got also some limitations like a relatively low Young's modulus; low alkaline resistance and low long-term strength due to stress rupture. in modern hybrid footbridges GFRP profiles are eagerly combined with conventional materials, like steel or concrete. There are only few all-GFRP footbridges reported in the literature, i.e. the cable-stayed Scripps Bridge in La Jolla, USA, Aberfeldy Bridge in Scotland, UK, Pontresina Bridge in Switzerland with a truss structural system and Fiberline

Corresponding author: b.stankiewicz@po.opole.pl 
Bridge in Kolding, Denmark (considered in this paper). However, the first all-GFRP footbridge in Europe was built in 1992 in Aberfeldy, Scotland with Maunsell composite system. All parts of Aberfeldy Footbridge like pylons, cables, beams, bridge deck and railing are made of GFRPs. Most of the connections between structure elements were erected using adhesive bonding. On the other hand, all components of Kolding Footbridge, beside the cables, were produced by pultrusion process, using Fiberline system and this whole medium size bridge was erected exclusively using mechanical fasteners [6]. A major concern for many bridge superstructures (decks/beams) is the significant reduction in durability and life expectancy caused by corrosion of the reinforcing steel and the corresponding deterioration of the concrete. As one of the solutions to this problem, structural applications of fiber reinforced polymer (FRP) composites have recently been attractive in the civil engineering. The aim of the investigation created by Siwowski et al. [7] were static tests of the full-scale hybrid FRP/RC girder and to present testing results in terms of its general behavior, carrying capacity, failure modes and FEM model validation. The research program created by Chróścielewski and Wilde et al. [8] was greatly expanded beyond the typical set of all-GFRP bridge acceptance tests. It was divided into two main parts: static - two ballast settings and dynamic - pedestrian forcing, modal hammer and an exciter. Due to its span, the theoretical object should be considered as small, but due to the cognitive aspects resulting from its unique character, a large number of monitored parameters have been adopted. During tests, a total of 216 various types of measurement points were used to identify the behavior of the structure. A laser scanning was performed on one side of the composite GFRP girder [8]. The novel idea of an all-composite structural system for road bridges has been proposed for the first time in Poland by Siwowski et al. [9]. To develop an understanding of the long-term performance of the FRP bridge, a monitoring scheme utilizing distributed fibreoptic sensors was implemented to assess any changes in the bridge structural behavior.

Is should be noted that the literature on the dynamic performance of all-GFRP bridges is rather limited and still insufficient. The flexural behavior of GFRP beams or trusses and dynamic parameters of GFRP bridges in full-scale were investigated by some researchers. Some contemporary achievements in this field are presented in the papers [10-14], however, the serviceability problems of such structures were not investigated.

In the contribution results of dynamic in-situ tests of cable-stayed span of all-GFRP Kolding Footbridge are presented. The vibration measurements of the footbridge were carried out and examined by the authors of this paper. The experimentally identified dynamic characteristics as well as the response of the studied footbridge under human excitation (walking and running) are given and discussed. Firstly, to estimate the dynamic properties of the footbridge, a series of freedecay responses under human jumping were conducted applying accelerometers. Seven natural frequencies, corresponding mode shapes and damping ratios were identified. The fundamental frequency of the analyzed structure was within a critical frequency range described by selected design guidelines, i.e. Eurocode [15] and technical guide Sétra [16]. In this case, the risk of pedestrian-induced resonance may appear and further investigations with respect to the maximum acceleration threshold were required. A methodology for footbridge classification with regard to their dynamic sensitivity was worked out and the correlation between the structure's properties and its dynamic response under pedestrian excitation was formulated. It was found that the analyzed footbridge fulfilled vibration comfort criteria elaborated by technical guide Sétra, however more restricted acceleration limits suggested by Eurocode were not met.

\section{Characteristics of analyzed footbridge}

The cable-stayed Kolding Footbridge was constructed in 1997 using 12 different pultruded composite profiles all made of Fiberline Glass Fiber Reinforced Polymer. The bridge structure is crossing an overhead main railway line near a salt water fjord in Kolding city, Denmark. In spite of these detrimental environmental conditions, the expected exploitation period of footbridge is minimum 100 years. The view of the structure with its longitudinal and cross-sections are shown in Fig. 1.

The primary aim of previous papers was to study changes in dynamic characteristics and the structural stiffness of the cable-stayed Fiberline Bridge made entirely of Glass Fiber Reinforced Polymer (GFRP) composite exploited for 20 years in the fjord area of Kolding, Denmark. Due to this specific location the bridge structure was subjected to natural aging in harsh environmental conditions with temperature amplitudes, solar radiation, as well as salty moisture in the air around the Kolding costal area [17-18].

The structural system of the footbridge deck comprises two I-shaped pultruded Fiberline profiles with a height of $1.4 \mathrm{~m}$ used as the main composite girders. Kolding Footbridge has two continuous spans with lengths of 27.9 and $12.4 \mathrm{~m}$, supported by a single A-shaped $18.5 \mathrm{~m}$ tall pylon. Four pairs of cables with a square cross-section are secured to the top of the pylon. The upper belt of the girders was designed from C-profiles with dimensions of $200 \times 60 \times 10 \mathrm{~mm}$ and $75 \times 75 \times 8 \mathrm{~mm}$, being the handrail of the balustrade. Additional protection against buckling was made of transverse and longitudinal ribs constructed from angle beams with dimensions of $100 \times 100 \times 10 \mathrm{~mm}$ and $75 \times 75 \times 8 \mathrm{~mm}$, with a distance of $1.55 \mathrm{~m}$ and $0.73 \mathrm{~m}$ respectively. The platform deck was made of composite platform gratings with a thickness of $50 \mathrm{~mm}$. The supporting structure of the deck comprises cross-bars with C-shaped profiles and dimensions of $240 \times 72 \times 12$ $\mathrm{mm}$, and side-bars with I-shaped profiles and dimensions of 200x100x10 mm. The outer dimensions of the pylon are varying from $5.22 \times 1.29 \mathrm{~m}$ at the bottom to $1.39 \times 0.49$ $\mathrm{m}$ in the upper part of the pylon. Total weight of the bridge is just 12 tones, while the designed load capacity is $500 \mathrm{~kg} / \mathrm{m}^{2}$. 
a)

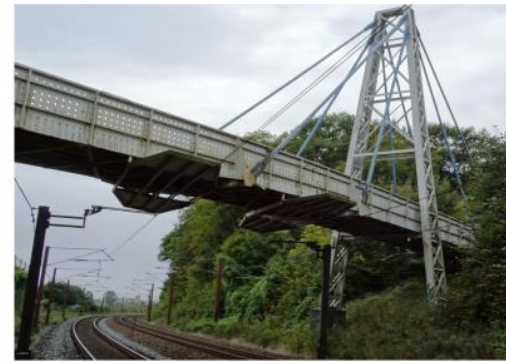

b)

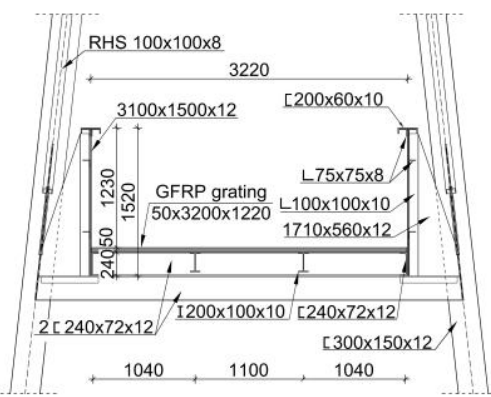

c)

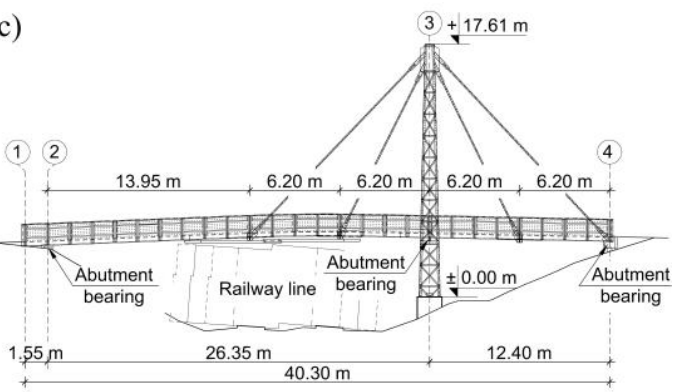

Fig. 1. Fiberline Footbridge in Kolding: (a) general view, (b) cross-section and (c) longitudinal section

\section{Results of dynamic tests of Kolding Footbridge}

\subsection{Normalized mode shapes and damping ratios corresponding to natural frequencies}

The modal parameters of the Kolding Footbridge, i.e. the corresponding natural frequencies, mode shapes and damping ratios were identified based on free-decay vibrations under human jumping excitations classically measured using accelerometers. Two high sensitivity accelerometers type PCB 3711E112G, based on the Micro-Electro-Mechanical System (MEMS) technology were used during in situ tests. The measurement range of the sensors was $\pm 2 \mathrm{~g}$, the frequency range $0-400 \mathrm{~Hz}$, the broadband resolution $0.1 \mathrm{mg} \mathrm{rms}$ in 0.5 to $100 \mathrm{~Hz}$ bandwidth, and the spectral noise $15 \mu \mathrm{g} / \sqrt{\mathrm{Hz}}$ in 1 to 100 $\mathrm{Hz}$ bandwidth. In total 28 measurement points were chosen directly on the upper edge of the two main girders, mainly within $3.1 \mathrm{~m}$ distance along the longitudinal axis of the girders. The human jumps were performed on the footbridge deck, in the middle of the longer span. Free vibration responses of the bridge were recorded during at least $25 \mathrm{~s}$ with the sampling rate of $200 \mathrm{~Hz}$

The Peak Picking and Frequency Domain Decomposition approaches were applied to identify the natural frequencies and mode shapes of the footbridge deck. A total of seven modal frequencies of the footbridge were identified, i.e. $f_{01}=4.35 \mathrm{~Hz}, f_{02}=6.49 \mathrm{~Hz}$, $f_{03}=11.12 \mathrm{~Hz}, f_{04}=12.06 \mathrm{~Hz}, f_{05}=15.38 \mathrm{~Hz}, f_{06}=17.11 \mathrm{~Hz}$, and $f_{07}=20.22 \mathrm{~Hz}$. The corresponding damping ratios (as a fraction of critical damping) were extracted based on filtered modal decays using the least square curve fitting method. The obtained damping ratio values, corresponding to seven modes of the deck of the Kolding Footbridge are $\xi_{1}=2.77 \%, \quad \xi_{2}=1.59 \%, \quad \xi_{3}=2.21 \%$, $\xi_{4}=0.68 \%, \xi_{5}=0.52 \%, \xi_{6}=1.91 \%$, and $\xi_{7}=2.43 \%$. The normalized mode shapes of the bridge deck, corresponding natural frequencies and damping ratios of the analyzed footbridge are presented in Fig. 2.

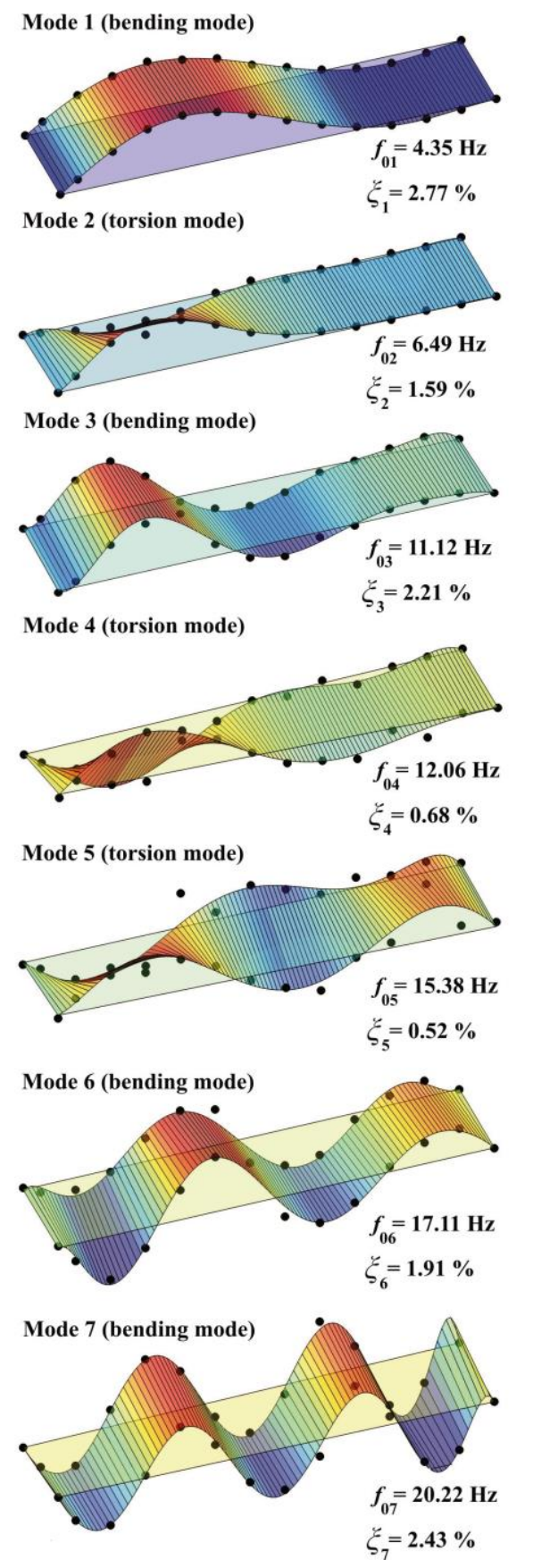

Fig. 2. Experimentally identified normalized mode shapes, corresponding natural frequencies and damping ratios of the Kolding Footbridge. 
The modes No. 1, 3, 6, and 7 are vertical bending type of modes, while the modes No. 2, 4, and 5 are torsion type of modes of the footbridge deck.

The comparison of the estimated damping ratios of the Fiberline Bridge with data published in the literature for selected footbridges made of various conventional materials showed that the modal damping of the cablestayed footbridge in full made of GFRP composite is relatively high. The detailed descriptions of the methodology and results of dynamic characteristic investigations of the Kolding Footbridge are presented in the paper [17].

\subsection{Investigation of pedestrian induced vibration levels}

Actions exerted by pedestrians on footbridges may result in vibrational phenomena. In general, these phenomena usually do not have adverse effects on structure, although the user may feel some discomfort. Pedestrian footbridges are subjected mainly to the loads of the pedestrians walking or running on them. These two types of loading must be treated separately as there is a difference between them, i.e. when walking, there is always one foot in contact with the ground, but the same does not apply when a person starts to run. The type of load (walking or running), the force created comprises a vertical component and a horizontal component, it being possible to break down the horizontal component into a longitudinal component (along the axis of the footbridge) and a transverse component (perpendicular to the axis of the footbridge) [16].

To assess the serviceability performance of the selected footbridge under loading conditions, dynamic tests were performed under pedestrian walking and running excitation and the acceleration response of the bridge was collected from the sensors installed at different locations on the bridge as shown in Fig. 3 (measurement points No. 1 and No. 2).

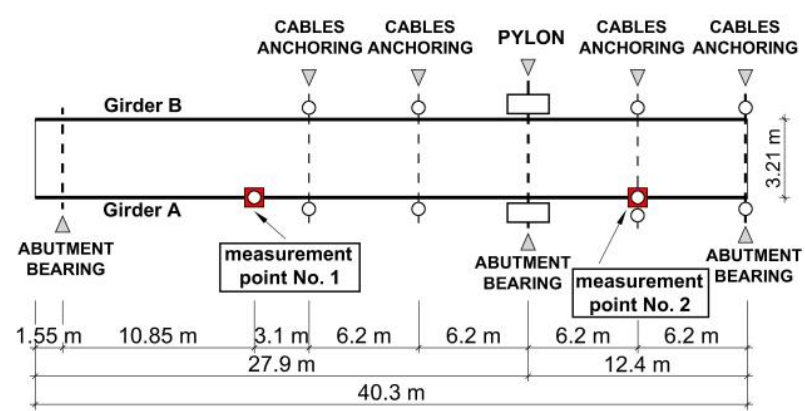

Fig. 3. Locations of the measurement points No. 1 and No. 2 on the girder denoted as " $\mathrm{A}$ " of the footbridge.

The filed, comprehensive tests involved the investigation of the dynamic vertical response induced by one walking person, two walking pedestrians, then one running person and two running footbridge users. Representative results of vertical acceleration responses of the footbridge under four independent dynamic load cases and their Power Spectral Density (PSD) functions are presented in Figs 4-7.
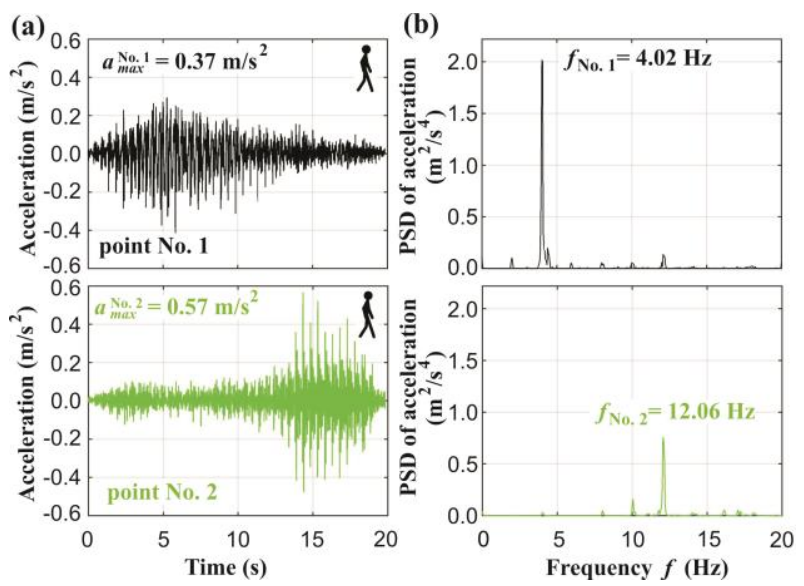

Fig. 4. (a) Vertical acceleration responses of two spans of the Kolding Footbridge recorded at measurement points No. 1 and No. 2 induced by one walking person and (b) their PSDs.
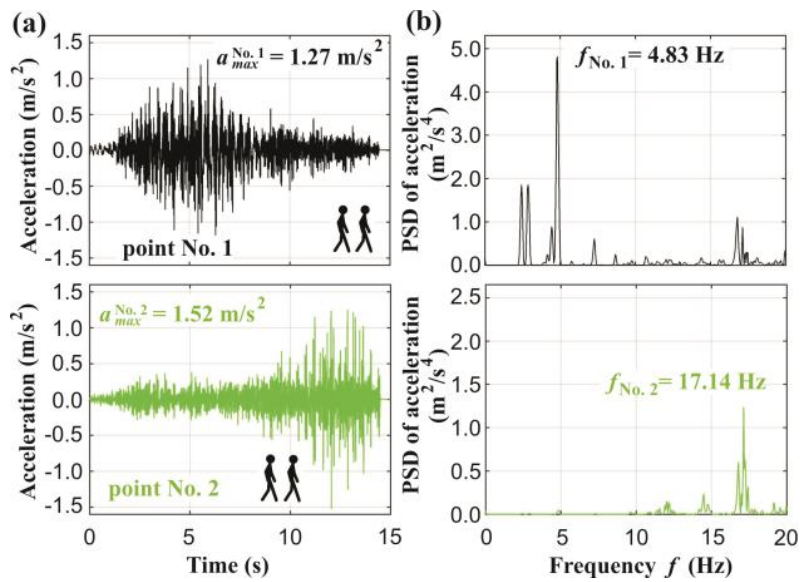

Fig. 5. (a) Vertical acceleration responses of two spans of the Kolding Footbridge recorded at measurement points No. 1 and No. 2 induced by two synchronized walking persons and (b) their PSDs.

(a)
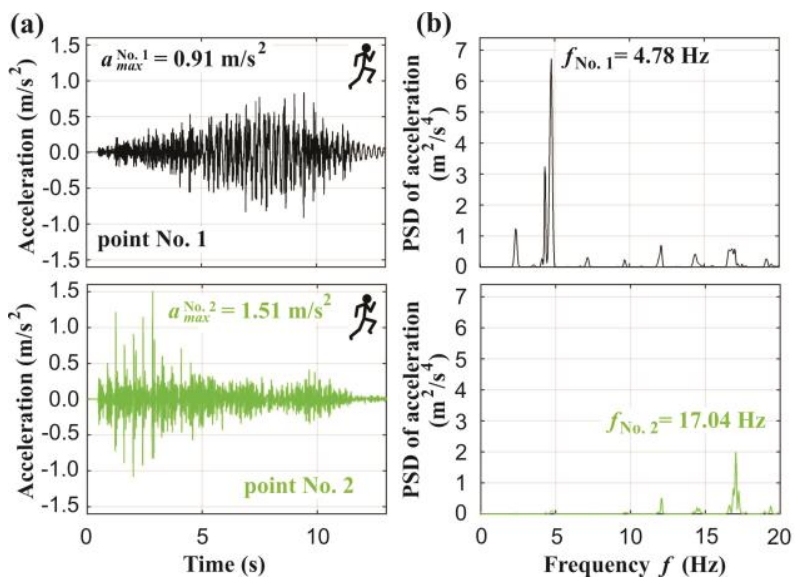

Fig. 6. (a) Vertical acceleration responses of two spans of the Kolding Footbridge recorded at measurement points No. 1 and No. 2 induced by one running person and (b) their PSDs.

The measurement of the bridge dynamic response under human excitation is needed to assess the comfort criteria for the natural frequency of the selected footbridge in the vertical direction falls within the critical frequency range. Acceleration time histories in 
vertical direction were collected from the pedestrian interaction tests. The collected data included acceleration records over the course of tests for all of the succeeding loading scenarios. The maximum dynamic response (vertical vibrations) of the footbridge induced by two running persons at measurement point No. 1 is $a^{\text {No. }}=1.87 \mathrm{~m} / \mathrm{s}^{2}$ and at the second measurement point (No. 2) the value of acceleration is $a^{\text {No. } 2}=1.79 \mathrm{~m} / \mathrm{s}^{2}$ (see Fig. 7a). The corresponding dominant frequencies of the excited vibrations existing on the PSD of the footbridge responses are $f_{\text {No. } 1}=3.08 \mathrm{~Hz}$ and $f_{\text {No. } 2}=17.14 \mathrm{~Hz}$, respectively (see Fig. 7b).
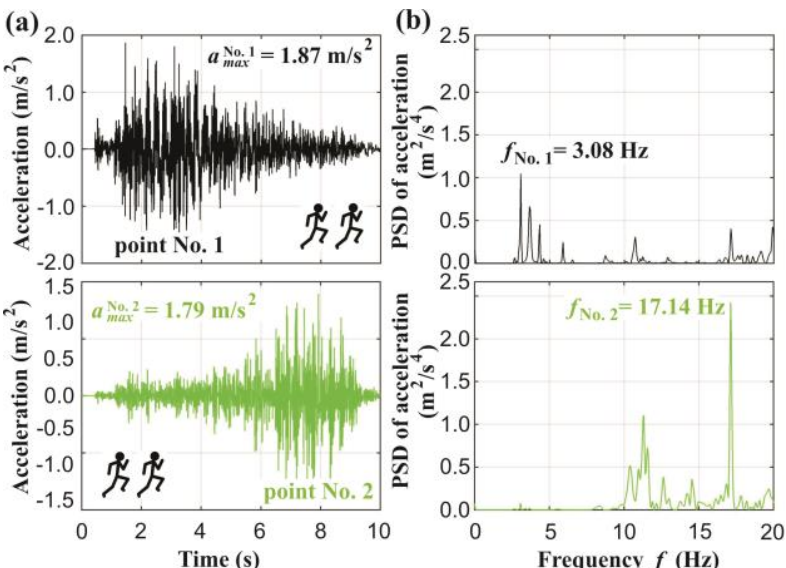

Fig. 7. (a) Vertical acceleration responses of two spans of the Kolding Footbridge recorded at measurement points No. 1 and No. 2 induced by two synchronized running persons and (b) their PSDs.

It should be noted that footbridges in their service life are submitted to simultaneous actions of several persons and this makes the corresponding dynamic much more complicated. In fact, each pedestrian has its own characteristics (weight, frequency, speed) and, according to the number of persons present on the bridge, pedestrians will generate loads which are more or less synchronous with each other, on the one hand, and possibly with the footbridge, on the other. Added to these, there are the initial phase shifts between pedestrians due to the different moments when each individual enters the footbridge [16]. Such complex load cases were not analyzed within the framework of the presented study, however, more comprehensive study is recommended.

\subsection{Evaluation of comfort criteria}

In the next step the results of dynamic testing were compared with vibration comfort criteria for footbridges, elaborated by Sétra [16] and Eurocode [15], taking into account frequency of vibration occurrence (frequent, rare and intentional events). The criteria are applicable in case of vibration sensed by pedestrians walking on the bridge deck (pedestrians in motion). According to the guidelines presented in the Eurocode international standard [15], the maximum vertical accelerations of spans of newly designed footbridges should not exceed of $0.7 \mathrm{~m} / \mathrm{s}^{2}$. Much more advanced recommendations are shown in the technical guide (Sétra) [16]. It these recommendations four classes of comfort criteria were formulated for footbridges regarding the accelerations measured in the horizontal and vertical directions.

The results obtained for the Fiberline Footbridge from the field tests, regarding the guidelines outlined in the international standard [15] and the technical guide [16] are presented in Fig. 8. The analysis of the acceleration collected records allowed concluding that the maximum vertical acceleration has reached values of $1.8 \mathrm{~m} / \mathrm{s}^{2}$, for double running by two persons. These values would allow classifying of the footbridge as providing a minimal comfort level according to the technical guide (Sétra) [16].

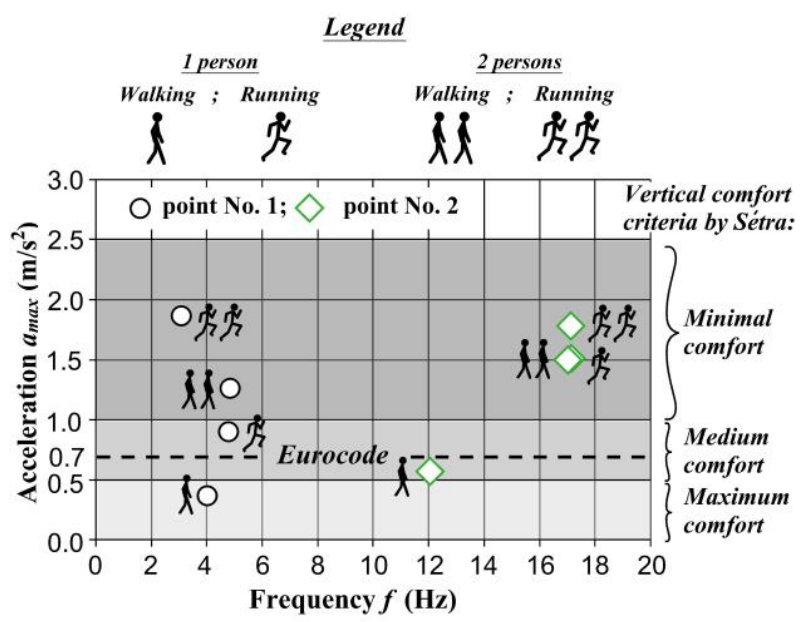

Fig. 8. Evaluation of vertical comfort criteria of the Fiberline Footbridge by Eurocode [15] and Sétra guidelines [16].

The values of maximum vertical accelerations scored in the measurement deck points No. 1 and 2 (see Fig. 3) induced by single walking person are $a^{\text {No. }}=0.37 \mathrm{~m} / \mathrm{s}^{2}$ and $a^{\text {No. }}=0.57 \mathrm{~m} / \mathrm{s}^{2}$, respectively (see Figs 4 and 8 ). These levels of accelerations are within the approvable range given in the international technical standard (Eurocode) [15], i.e. below the value of $0.7 \mathrm{~m} / \mathrm{s}^{2}$. The vertical accelerations induced by the synchronous walking and running of two footbridge users as well as single running person, do not meet the requirements given in the Eurocode standard.

The in situ identified dominant frequencies of footbridge vibrations under human excitations show that uncertainty in respect to the predicted dynamic properties of all-GFRP structure like cable-stayed Kolding Footbridge is inevitable.

\section{Concluding remarks}

As a result of using new high strength structural materials contemporary footbridges are characterized by small cross sectional dimensions and long spans. Mass and stiffness of the structures are decreased. The structures become susceptible to various dynamic actions. Fundamental vibration frequency of the lightweight and slender footbridges often appears in frequency range of human actions. In some cases, fulfilment of the serviceability limit state (i.e. vibration 
comfort criteria) of these footbridges can be important [19]. Basing upon the obtained results, following general conclusions can be formulated:

- The experimentally identified natural frequencies of the Kolding Footbridge are $f_{01}=4.35 \mathrm{~Hz}, f_{02}=6.49 \mathrm{~Hz}$, $f_{03}=11.12 \mathrm{~Hz}, f_{04}=12.06 \mathrm{~Hz}, f_{05}=15.38 \mathrm{~Hz}, f_{06}=17.11 \mathrm{~Hz}$ and $f_{07}=20.22 \mathrm{~Hz}$, while the obtained damping ratio values, corresponding to seven bending and torsion modes are $\zeta_{1}=2.77 \%, \zeta_{2}=1.59 \%, \zeta_{3}=2.21 \%, \zeta_{4}=0.68 \%$, $\zeta_{5}=0.52 \%, \zeta_{6}=1.91 \%$ and $\zeta_{7}=2.43 \%$. The collected information from fundamental dynamic characteristics study would be very useful for the procedure of the calculation model verification, the computation model updating or dynamic response prediction.

- Rare events (e.g. running persons) can be very important dynamic load case in evaluation of comfort criteria of standing and walking persons especially in case of structures situated in recreation areas or touristic places.

- In case of synchronized action of more than one running persons amplitudes of footbridges vibrations can achieve large values and create minimal comfort criteria. The analysis of the acceleration collected records permitted to conclude that the maximum vertical acceleration reached values of $1.8 \mathrm{~m} / \mathrm{s}^{2}$, for two running persons.

- The maximum vertical accelerations recorded in the measurement points No. 1 and 2 (see Fig. 3) induced by one walking person are $a^{\text {No. } 1}=0.37 \mathrm{~m} / \mathrm{s}^{2}$ and $a^{\text {No. }}=0.57 \mathrm{~m} / \mathrm{s}^{2}$, respectively (see Figs 4 and 8 ). These values are within the acceptable range given in the Eurocode international standard [15], i.e. below the value of $0.7 \mathrm{~m} / \mathrm{s}^{2}$.

- The vertical accelerations induced by the synchronous walking and running of two persons as well as one running person do not meet the requirements given in the Eurocode standard [15]. In case of synchronous running of two persons the acceptable accelerations were exceeded more than two and a half times.

- The recorded values of vertical acceleration of the considered footbridge were also analyzed according to the comfort criteria given in the technical guide (Sétra) [16]. In this case, the maximum comfort criterion was met at the measurement point No. 1 in case of one walking person. In this case the maximum vertical acceleration was $a^{\text {No. } 1}=0.37 \mathrm{~m} / \mathrm{s}^{2}$ (see Figs 4 and 8 ). The accelerations recorded at the point No. 2 induced by one walking person and at the point No. 1 induced by one running person met the medium comfort criteria. However, the other values of the recorded accelerations are within the range of the minimum comfort criteria.

All in-situ dynamic tests as well as numerical and computational analyzes for Kolding Footbridge were developed jointly by the authors of the paper.

\section{References}

1. E. Caetano, A. Cunha, C. Moutinho, F. Magalhaes, Eng. Struct. 32, 1082-1091 (2010)

2. R. Sachse, A. Pavic, P. Reynolds, J. Sound Vib. 274, 461-480 (2004)
3. P. Hawryszków, Proc. of $5^{\text {th }}$ Int. Conf. "Footbridge 2014", London, England, July 16-18, ID 10070939 (2014)

4. K. Żółtowski, Proc. of $5^{\text {th }}$ Int. Conf. "Footbridge 2014", London, England, July 16-18, ID 10070958 (2014)

5. C. Meinhardt, Footbridge Vibration Design (CRC Press, London, 2009)

6. B. Stankiewicz, GFRP Bridge panel by material and FEM analysis (Lambert Academic Publishing, Saarbrücken, 2015)

7. M. Rajchel, T. Siwowski, J. Civil Eng., Envir. Arch. 62, 363-377 (2015)

8. L. Pyrzowski, M. Miśkiewicz, J. Chróścielewski, K. Wilde, Mater. Sci. Eng. 245, 228-233 (2017)

9. T. Siwowski, D. Kaleta, M. Rajchel, Compos. Struct. 192, 555-567 (2018)

10. F. Ascione, G. Mancusi, S. Spadea, M. Lamberti, F. Lebon, A. Maurel-Pantel, Compos. Struct. 131, 5565 (2015)

11. D. Bačinskas, A. Rimkus, D. Rumšys, A. Meškėnas, S. Bielinis, A. Sokolov, T. Merkevičius, Procedia Engineering 172, 68-74 (2017)

12. Y. Bai, T. Keller, Compos. Struct. 82(1), 90-100 (2008)

13. H.S. Ji, W. Song, Z.J. Ma, Eng. Struct. 32, 28142824 (2010)

14. R. Votsis, T. Stratford, M. Chryssanthopoulos, Steel Comp. Struct. 23(2), 205-215 (2017)

15. PN-EN 1990:2004/A1:2008 Eurocode. Basis of structural design (1990)

16. Sétra, Technical guide. Assessment of vibrational behaviour of footbridges under pedestrian loading (Sétra/Association Française de Génie Civil, Paris, 2006)

17. P. Górski, B. Stankiewicz, M. Tatara, Proc. of Conference on Dynamics of Civil Engineering and Transport Structures and Wind Engineering "DYNWIND'2017”, Brezovica, Slovak Republic, May 2125 (2017), ID 00005

18. B. Stankiewicz, J. Compos. Mater. 51, 2301-2313 (2017)

19. M. Pańtak, Proc. of $4^{\text {th }}$ Int. Conf. "Footbridge 2011", Wroclaw, Poland, July 6-8, 1209-1214 (2011) 